\title{
AS INTERFASES DA QUALIFICAÇÃO DO TRABALHADOR BRASILEIRO NO CONTEXTO DA MUNDIALIZAÇÃO DO CAPITAL
}

\section{THE INTERFACES OF THE QUALIFICATION OF BRAZILIAN WORKERS IN THE CONTEXT OF GLOBALIZATION OF CAPITAL}

\author{
Enéas Arrais Neto* \\ Keyla de Souza Lima Cruz**
}

\section{RESUMO}

Este trabalho visa refletir acerca da relação dialética entre educação e trabalho, inserido no contexto de Mundialização do Capital e seus rebatimentos na qualificação profissional dos trabalhadores. Para tanto, o presente estudo é uma pesquisa bibliográfica, cujas leituras têm como núcleo central a relação entre trabalho e educação a partir de uma perspectiva histórico-dialética. Destacamos que o aporte teórico deste estudo é subsidiado pelo pensamento de Chesnais (1996), Alves (1999), Antunes (2010), Cunha (2000) e Ramos (2002). Consideramos que a relação entre educação e trabalho no contexto de Mundialização do Capital é resignificada, uma vez que no processo de Internacionalização do Capital ocorre uma remodelagem do espaço produtivo a nível mundial, além do acirramento da concentração de riqueza, acarretando na concorrência entre os trabalhadores e na exigência por qualificação profissional de acordo com as demandas do mercado de trabalho. Essa processualidade atinge profundamente a educação profissional brasileira, cujos rebatimentos recaem na priorização de uma formação pautada na flexibilidade e na polivalência, de modo a atender as exigências da globalização e da crise do emprego.

PALAVRAS-CHAVE: Mundialização do Capital, Trabalho, Educação Profissional e qualificação profissional

\section{ABSTRACT}

This study aims to reflect about the dialetic relation between education and work, in the context of the capital globalization, and its effects in the workers professional qualification. Thus, the present study is a literature research, whose reading emphasize the relation between work and education from a historical-dialectical perspective. The research is based on Chesnais (1996), Alves (1999), Antunes (2010), Cunha (2000) and Ramos (2002) studies. We consider that the relation between education and work in the context of capital globalization is re-signified, whereas, in the internationalization process of capital, takes place a change in the current production system in the world, and the intensification of the concentration of wealth, leading in a competition between workers and leading in the requirement for professional qualification in accordance with the demands of the labor market. This 
effects deeply Brazilian professional education, whose repercussions demands priority an education based on flexibility and versatility to attend the demands of globalization and the crisis of employment.

KEYWORDS: Capital Globalization, Work, Professional Education and Professional Qualification.

\section{INTRODUÇÃO}

A relação entre trabalho e educação deve ser entendida a partir de sua inserção na tessitura das relações sociais, de modo a apreender as suas repercussões na educação profissional brasileira, particularmente na qualificação dos trabalhadores. Essa processualidade nos permite uma aproximação da realidade, de modo a ultrapassar os fenômenos imediatos para o desvelamento de sua totalidade dialética.

É no âmbito de profundas mudanças tecnológicas e organizacionais do trabalho, a partir dos anos de 1980, marcadas pela flexibilização da produção e reestruturação das ocupações, que verificamos uma valorização dos saberes dos trabalhadores não ligados ao trabalho prescrito ou ao conhecimento formalizado. Assim, reacendem-se estudos de cunho sociológico e pedagógico sobre qualificação profissional e a emergência da noção de Competência (RAMOS, 2002).

Sendo assim, o tensionamento da qualificação pela noção de Competência enfatiza os saberes tácitos e sociais sob os saberes formais, esta atestada normalmente pelos diplomas, além de valorização dos atributos subjetivos, sob a forma de capacidades cognitivas, socioafetivas e psicomotoras (Ibidem, 2002).

Estas tendências acarretam num processo de reordenamento da educação profissional brasileira, cabendo muitas vezes à escola o papel de garantir uma "formação" adaptável aos ditames do processo de globalização e à crise do emprego. Nesse contexto, a qualificação profissional é resignificada pela noção de competência que garantirá condições de empregabilidade ao trabalhador.

Para tanto, o presente estudo é uma pesquisa bibliográfica, cujas leituras têm como núcleo central a relação entre trabalho e educação a partir de uma perspectiva histórico-dialética, cujo processo produtivo é analisado no contexto de Mundialização do Capital (CHESNAIS,1996). Contudo, torna-se imprescindível problematizar as repercussões dessa processualidade na educação profissional, com 
rebatimentos na formação do trabalhador, subsidiados pelo pensamento de Antunes (2010), Cunha (2000) e Ramos (2002) a partir de uma perspectiva dialética de apreensão da realidade, tendo por base Kosik (1976).

\section{TRABALHO E EDUCAÇÃO NO CONTEXTO DE MUNDIALIZAÇÃO DO CAPITAL}

A relação entre trabalho e educação na sociedade capitalista vem sendo foco de estudos e pesquisas, no âmbito da sociologia, no que diz respeito à formação do trabalhador e sua adequação aos regimes de produção capitalista. Desta forma torna-se imprescindível discorrer, ainda que brevemente, sobre o contexto de crise estrutural do Capital, com recorte temporal da década de 1970, em que surge o novo complexo de reestruturação produtiva, implicando em profundas mudanças no mundo do trabalho organizado e conseqüentemente na formação do trabalhador.

A análise desse processo parte de uma compreensão das relações sociais, políticas e econômicas que impulsionaram num redimensionamento das formas de reestruturação produtiva.

Nos últimos 20 - 30 anos do século XXI emerge um novo período de desenvolvimento do Capitalismo Mundial, caracterizado por "Mundialização do Capital" cujo regime de acumulação capitalista insere-se num processo de internacionalização do Capital. Esse novo período se desenvolve no bojo de uma "crise de superprodução de valores de troca". (MENDEL, 1990:211), sendo caracterizado, por alguns autores, pela "produção destrutiva" (MÉSZÁROS, 2009), pela "acumulação flexível" (HARVEY, 1993) ou ainda por um período caracterizado pelo domínio do capital especulativo sobre o produtivo, resultante da política de desregulamentação e liberalização promovida pelos Estados Unidos e pela Inglaterra desde o final dos anos 70 e início dos anos 80 (CHESNAIS, 1996).

A Mundialização do Capital deve ser analisada sob duas perspectivas: 1) é um regime "institucional internacional político e econômico específico", cujo principal beneficiário é o Capital concentrado nas empresas transnacionais (ETNs), nos bancos internacionais e nas organizações internacionais (investidores financeiros recentes); 2) designa um período historicamente novo de pleno desenvolvimento das contradições fundamentais do movimento de acumulação do 
Capital que irão se alastrar de maneira planetária (IBIDEM, 1996)

Para o entendimento deste processo é imprescindível o entendimento das determinações políticas e econômicas, as quais são analisadas pelo autor supra mencionado, tomando por base as relações entre Capital e Estado, assim como entre Capital e Trabalho.

A consolidação desse novo regime Institucional internacional nos anos de 1990 ocorreu mediante um conjunto de fatores, com destaque no papel dos instrumentos jurídicos na criação de um quadro atual de liberalização e desregulamentação do movimento de Capitais, troca e investimentos diretos (CHESNAIS, 2008, p.15). Tal política garantiu liberdade de circulação e de ação das empresas transnacionais, bancos internacionais e investidores internacionais, buscando a valorização do dinheiro que gera mais dinheiro.

A característica predominante desse novo regime de acumulação capitalista é ser rentista e parasitário, cujo funcionamento e modo de reprodução são comandados pelas prioridades do capital-dinheiro concentrado.

\footnotetext{
Esse capital-dinheiro, ou capital financeiro vive de rendas que derivam da partilha da mais-valia, isto é, em dedução do lucro bruto de exploração do capital industrial. As figuras ou as modalidades de valorização cada vez mais variadas que o capital dinheiro imaginou derivam todas daquela do capital portador de juros, do qual Marx diz que ela é "a forma mais reificada, a mais fetichizada da relação capitalista” (CHESNAIS, 1996, p. 64).
}

Contudo, é válido destacar que isso foi possível em virtude de um conjunto de fatores tais como: a ofensiva do capital adquirida em decorrência da acumulação dos "trinta anos gloriosos"; a utilização de novas tecnologias pelas corporações transnacionais, visando concorrer com os dos grupos japoneses e modificar suas relações com os trabalhadores; e finalmente o apoio dos Estados capitalistas, sob a forma de políticas de liberalização, desregulamentação e privatização (ALVES, 1999).

A consolidação da Mundialização do Capital acentuou mecanismos de descentralização do Capital e conduziu a polarização da riqueza e consequentemente evolução dos sistemas políticos, no que diz respeito ao domínio das oligarquias econômicas e políticas. É válido destacar que a polarização não são exclusivos do Norte. O Regime Institucional Internacional 
reforçou os direitos de exploração do trabalho e ou remuneração rentista. Esse processo não impediu as tensões entre países do Norte e Sul e a tensão entre frações do Capital concentrado internacionalizado, acarretando remodelagem do espaço mundial de relações econômicas e políticas. (CHESNAIS, 1996).

A liberalização da economia ameaça os assalariados, haja vista a necessidade de mudança dos locais de produção para os países onde a mão-deobra é barata e os assalariados são pouco protegidos; ou ainda a instalação de redes de produção terceirizadas.

O processo de internacionalização do Capital acarreta na concorrência direta e seletiva dos trabalhadores, sendo exigido simultaneamente duas qualidades: níveis significativos de produtividade de trabalho e diferenciação de níveis salariais, dependendo dos países de origem dos investimentos diretos ou a existência de massa de trabalhadores terceirizados ou dos gastos com as despesas de proteção social (saúde, aposentadorias e seguro-desemprego). Quando mencionamos a capacidade de produtividade crescente, estamos nos referindo aos "níveis de formação e qualificação dos assalariados ou métodos de colocação no trabalho e de disciplinas próprias à história política e industrial dos diferentes países". (CHESNAIS, 2008, p. 28).

\section{QUALIFICAÇÃO PROFISSIONAL E AS TRANSFORMAÇÕES NO MUNDO DO TRABALHO}

Para Antunes (2010) as mudanças no mundo do trabalho foram tão intensas que atingiu diretamente a classe que vive do trabalho ${ }^{1}$ no que diz respeito a sua materialidade, bem como sua subjetividade. Estas mudanças acarretam em algumas tendências, a destacar: emergência de formas desregulamentadas de trabalho, acarretando na redução do conjunto de trabalhadores estáveis; surgimento de um novo proletariado fabril (os terceirizados, subcontratados, part-time, entre outros); e a exclusão de jovens com idade de ingresso no mercado de trabalho, que sem perspectivas de emprego acabam, muitas vezes, inserindo-se nos trabalhos precarizados ou mesmos fazendo parte da parcela cada vez mais numerosa de desempregados.

Nesse ínterim, assiste-se ao incremento da automação, da robótica e da 
microeletrônica no universo fabril, em que antes predominava o regime de produção Fordista/Taylorista - caracterizado pela produção em massa; através da linha de montagem e de produtos mais homogêneos, através do controle dos tempos, da existência do trabalho parcelar; e pela fragmentação das funções. Sendo assim, ao mundo da produção vão se mesclando outros processos produtivos (neofordismo, neotaylorismo e pós-fordismo) que vão influenciar vários países do Capitalismo Globalizado. (IBIDEM, 2010).

Contudo, o autor alerta que é imprescindível o entendimento do trabalho, enquanto elemento estruturante da sociedade para a apreensão das tendências em curso quais sejam: processo de intelectualização do trabalho fabril, demandando uma maior qualificação profissional e /ou processo de desqualificação ou subproletarização da classe que vive do trabalho.

Para tecermos algumas reflexões sobre essa problemática é imprescindível estabelecer uma análise relacional entre tecnologia e qualificação profissional sem perder de vista a rede de relações sociais que as engendram.

No contexto de flexibilização da produção e reestruturação das ocupações há o tensionamento pela polivalência dos trabalhadores e valorização dos saberes dos mesmos não ligados ao trabalho prescrito ou ao conhecimento valorizado. Estudos e pesquisas recuperam o debate sobre a qualificação, ao mesmo tempo em que emerge a noção de competência.

Segundo Hirata (1996 apud ARRAIS NETO, 2006) a noção de competência surge do discurso empresarial francês, enquanto uma proposta póstaylorista assimilada pelos empresários europeus, visando implementar mudanças na organização do trabalho. Contudo, verificamos uma tendência de utilização do conceito de competência como sinônimo de qualificação, sendo necessária uma análise de suas dimensões.

Sendo assim, a qualificação pode ser vislumbrada sob três dimensões correlacionadas:

1) Dimensão conceitual: qualificação enquanto conjunto de conhecimentos teóricos e científicos, formalizados pelos diplomas e títulos;

2) Dimensão experimental: qualificação relacionada ao conteúdo real do trabalho em que se inscrevem não somente os conceitos, mas o conjunto 
de saberes em jogo quando da realização do trabalho (SCHWARTZ, 1995 apud RAMOS, 2002: 401).

Apresentamos ainda um terceiro enfoque em que a qualificação deve ser pensada no contexto das relações sociais, relacionada a uma elaboração coletiva detentora de uma conotação sociocultural e histórica.

RAMOS (2002) afirmar que o conceito de qualificação enquanto dimensão social permite estabelecer uma relação dialética entre os saberes e a configuração da divisão social e técnica do trabalho. Em outras palavras, reconhece que a qualificação está inserida numa dinâmica social, síntese das dimensões conceitual, experimental e social.

Para Arrais Neto (2006) o conceito de qualificação ainda é atual e dá conta de compreendermos as contradições das relações sociais no mundo do trabalho. Ademais, a noção de competência está ancorada numa dimensão individual, que subestima a dimensão social das relações sociais de trabalho.

Sendo assim, o redimensionamento do conceito de qualificação tem implicações não somente técnicas, mas também políticas. No século XXI vivenciamos processos de globalização da economia e crise do emprego, implicando na criação de novos códigos que adequem a educação às tendências produtivas. Isso quer dizer que há a exigência de preparar os jovens para o mercado de trabalho, por meio da aquisição de competências, associadas às noções de empregabilidade e laborabilidade.

Contudo, apesar da importância dos títulos e diplomas para a inserção profissional, esses não garantem a permanência no mercado de trabalho, sendo necessário adquirir novas competências e atualizá-las constantemente, proporcionando ao trabalhador a empregabilidade. A aquisição e inovação desses conhecimentos pode ocorrer por meio da educação profissional ou pela diversidade das experiências profissionais, residindo este uma inovação proporcionada pelo conceito de competência: o reconhecimento do saber prático/tácito do trabalhador. (RAMOS, 2002).

Reconhecemos que as tendências em curso vivenciadas na atualidade contribuem para o enfraquecimento do conceito de qualificação pela competência. Isso traz implicações no âmbito econômico, social e educacional quais sejam: 
desfiliação dos trabalhadores do sistema de regulações sociais, dada as condições de precarização do trabalho e flexibilidade do processo de acumulação capitalista; e redução da educação profissional a formações restritas, desfocando para uma formação integral.

Estas tendências refletem na reforma da educação profissional brasileira dos anos de 1990, mas que devem ser analisadas tomando por base a consolidação do aparato educacional profissional no Estado Novo, marcado por uma forte intervenção do Estado no delineamento das políticas públicas educacionais a nível profissionalizante.

Cunha (2000) realizou importante estudo do ensino profissional industrial no século XX, no contexto de consolidação da industrialização no país, tendo o Estado Novo como elemento propulsor do desenvolvimento econômico. Para tanto, o autor parte da idéia de que a forma e a natureza do ensino profissional industrial sofreu forte influencia do corporativismo, entendido como expressão da articulação dos interesses públicos e privados. Nesse contexto político-econômico o grupo do empresariado utilizou o braço do Estado na garantia de seus interesses políticos, em detrimento dos interesses do operariado.

A repercussão desses acontecimentos garantiu condições para a consolidação da dualidade entre educação profissional e propedêutica, sendo esta destinado a classe trabalhadora e aquela as elites intelectuais. Desta forma a formação defendida pelo Estado e organismos internacionais girava em torno da busca de preparação de uma mão de obra apta ao desenvolvimento econômico, cujo enfoque era a garantia de lucratividade e o enfraquecimento da formação integral.

\section{A REDE FEDERAL DE EDUCAÇÃO PROFISSIONAL NA SOCIEDADE BRASILEIRA}

No contexto dos anos de 1970 e 1980, verifica-se um processo de complexificação da sociedade brasileira, advinda da intensificação do processo de crescimento industrial, propiciando uma teia de organizações sociais que vai moldando o comportamento e o encapsulamento da estrutura corporativa do Estado. Esse cenário não irá erodir o corporativismo, ao contrário, vai permitir criar novas formas de preservação dos interesses de grupos específicos: funcionários públicos, 
setores da burocracia federal, estadual e municipal e grupos privados. (CUNHA, 2000).

No final dos anos 1980 reacende o debate acerca da dualidade em torno do ensino médio e da educação profissional no país. Nesse contexto surge discurso político e ideológico de reforma da educação profissional: alto custo e inserção no ensino superior ao invés do mercado pelos egressos. Em 1989, o relatório do Banco Mundial embasou ainda mais essas discussões.

Nesse contexto surgem opiniões de dois importantes consultores do Ministério da Educação (MEC), a destacar Castro (1972, 1974, 1997) e Oliveira (1995) cujo teor das discussões se pauta na dualidade entre educação propedêutica e profissional. Houve incorporação das opiniões dos consultores no Governo do presidente Fernando Henrique Cardoso - FHC (1995 - 1998) destacando:

1) Separação entre a educação profissional e a propedêutica;

2) Flexibilização dos currículos com foco nas mudanças do mercado de trabalho;

3) Aproximação das escolas com empresariado, e incentivo do funcionamento autônomo das escolas técnicas e dos Centros Federais de Educação Tecnológica do Ceará (CEFETs)

Destacamos ainda que no Governo do presidente Fernando Henrique Cardoso (FHC) ocorreu à reforma da Educação Profissional, com destaque o Decreto 2.208/97 e a Portaria Ministerial 646/97 que radicalizaram a separação entre ensino médio (chamado acadêmico) e ensino profissional (denominado na LDB de educação profissional), proibindo-se, assim, o ensino integrado.

Para implementação dessa reforma o governo FHC lançou o Programa de Expansão da Educação Profissional (PROEP), visando a implementação e/ou a readequação dos 200 Centros de Educação Profissional.

No Governo do presidente Luis Inácio Lula da Silva, os Centros Federais de Educação Tecnológica do Ceará (CEFETs), juntamente com as escolas Agrotécnicas e Técnicas foram transformados agregando-se a rede federal de educação profissional por meio dos Institutos Federais de Educação, Ciência e Tecnologia (IFs). O Instituto Federal do Ceará foi criado em 29 de dezembro de 2008, mediante Lei no 11.892, congregando o extinto Centro Federal de Educação Tecnológica do Ceará (CEFETCE) e Escolas Agrotécnicas Federais de Crato e 
Iguatu. Desta forma, as Instituições de Ensino da Rede Federal passam a ser autarquias, detentoras de autonomia administrativa, patrimonial, financeira, didáticopedagógica e disciplinar, além de ofertar educação básica, técnica e superior.

A iniciativa de expansão e interiorização da rede federal de Educação Profissional pelo Governo do Presidente Luis Inácio Lula da Silva desencadeou em rebatimentos no desenvolvimento local e regional, haja vista que existe um atrelamento destas unidades de ensino com os arranjos locais, culturais e produtivos, visando garantir elevação da escolaridade e capacitação para o trabalho.

É válido ressaltar que a expansão da rede federal vem atrelada ao processo de interiorização, mediante a implantação dos Campi a nível local, visando o desenvolvimento econômico e "social" do entorno. Nesse sentido, como cada campus possui autonomia financeira e pedagógica, há uma tendência de ofertar cursos técnicos e tecnológicos condizentes com a realidade econômica. Este é o caso do Campus de Maracanaú.

O Campus de Maracanaú foi inaugurado em 13 de novembro de 2007, estando localizado no maior Distrito Industrial do Ceará, ofertando cursos técnicos no âmbito da automação industrial, informática, redes de computadores e meio ambiente, além de ofertar cursos de nível superior em Manutenção Industrial, Engenharia Ambiental Licenciatura em Química, Ciências da Computação. ${ }^{2}$

Diante da recente expansão e interiorização da rede federal de educação profissional, cuja intensificação se deu no Governo Lula, bem como da especificidade do entorno do Campus supra mencionado, destacamos a importância de aprofundamento de estudos e pesquisas no que diz respeito às implicações da reestruturação produtiva, organizacional e tecnológica do mundo do trabalho na qualificação profissional dos trabalhadores, advindos dos cursos técnicos e tecnológicos do IFCE - Campus de Maracanaú.

\section{CONSIDERAÇÕES FINAIS}

As repercussões do processo de Mundialização do Capital no trabalho e na educação foram consideradas neste trabalho, levando-se em considerações as relações sociais, políticas, econômicas e educacionais que engendram essa processualidade. 
O desenvolvimento tecnológico, aliado a internacionalização do Capital exige um novo perfil de trabalhador, cuja qualificação profissional vem sendo tencionada para o desenvolvimento de competências, cuja finalidade seria adquirir novas habilidades que Ihes garanta condições de empregabilidade num contexto de precarização e flexibilização do trabalho.

Não podemos deixar de mencionar 0 papel do Estado no desenvolvimento e consolidação do processo de financeirização da economia, desencadeando na destituição dos direitos dos trabalhadores em detrimentos dos ditames do Capital.

Destacamos, ainda, que o Estado brasileiro viabilizou o coroamento de um aparato educacional sob bases no corporativismo e patrimonialismo, em que o público e o privado se confundem de modo a tensionar as forças políticas em prol da classe empresarial, em detrimento dos trabalhadores.

Sendo assim, a dualidade da educação profissional se consolida na sociedade a partir de uma demanda do próprio Capital, cuja garantia de lucratividade está atrelada a capacidade do trabalhador se moldar aos processos produtivos de geração de mais valia.

Isto atinge a educação profissional brasileira no que diz respeito a adequação das diretrizes curriculares, bem como das legislações pertinentes a área de educação, tais como a Lei de Diretrizes e Bases da Educação( LDB) e decretos federais às demandas do mercado de trabalho. Há uma tendência de garantir uma formação aligeirada, certificada pelos conhecimentos tácitos dos trabalhadores, em detrimento de uma educação integral.

Neste Contexto, verificamos a expansão e interiorização da Rede Federal de Educação Profissional Brasileira, com destaque nos Institutos Federais de Educação, ciência e Tecnologia (IFs), de modo a garantir uma formação profissional que garanta o desenvolvimento econômico local. Contudo destacamos a importância de estudos e pesquisas na perspectiva de compreender as repercussões da globalização e desenvolvimento tecnológico na formação profissional destes futuros trabalhadores. 


\section{REFERÊNCIAS BIBLIOGRÁFICAS}

ALVES, Giovanni. Trabalho e Mundialização do Capital: a nova degradação do trabalho na Era da Globalização. 2 Ed. Londrina: Praxis - Free editions, 1999. Disponível em: < http://editorapraxis.cjb.net>. Acesso em abril de 2011.

ANTUNES, Ricardo. Adeus ao trabalho? Ensaio sobre as metamorfoses e a centralidade do mundo do trabalho. 14.ed. São Paulo: Cortez, 2010

ARRAIS NETO, Enéas (Org). Educação e Modernização Conservadora. In. A Essência da Reforma do Ensino Médio: Competências para o novo mundo do trabalho? Fortaleza: Edições UFC, 2006.

CASTRO, C. de M. O secundário: esquecido em um desvão do ensino? Textos para discussão MEC/INEP (Brasília), v.1, n.2, abr.1997

CASTRO, C. de M., ASSIS, M.P. de. Ensino Técnico - desempenho e custo. Rio de Janeiro: IPEA/INPES, 1974.

CAStro, C. de M., MELlO e SOUZA, A. de. Mão de obra industrial no Brasil: mobilidade, treinamento e produtividade. Rio de Janeiro: IPEA/INPES, 1972.

CHESNAIS, François. A mundialização do capital. São Paulo: Xamã, 1996.

.Mundialização do Capital e jogo da Lei da população inerente ao Capitalismo. In SOUSA, Antônia de Abreu (Org.). Trabalho, Capital Mundial e formação dos trabalhadores. Fortaleza: editora Senac Ceará; Edições UFC, 2008.

CUNHA, Luiz Antônio. O Ensino profissional na irradiação do industrialismo. São Paulo: Editora UNESP, Brasília, DF: FLACSO, 2000. 
HARVEY, David. Condição pós-moderna. São Paulo: Loyola, 1993.

KOSIK, Karel. Dialética do concreto. 5. ed. Rio de Janeiro: Paz e Terra, 1976.

MÉSZAROS, Istvan. A crise estrutural do capital. São Paulo: Boitempo, 2009.

MANDEL, Ernest. A crise do capital: os fatos e sua interpretação marxista. São Paulo: Ensaios, 1990.

OLIVEIRA, J.B.A. e. Repensa o ensino de segundo grau: subsídios para discussão. Ensaio-avaliação e políticas públicas em educação (Rio de Janeiro), v.3, n.8, jul./set.1995.

RAMOS, Marise Nogueira. A Educação Profissional pela pedagogia das competências e a superfície dos documentos oficiais. Educação e Sociedade, Campinas, p.401-422, 2002. Disponível em < http://www.cedes.unicamp.br>. Acesso em abril de 2011.

* Graduado em Arquitetura e Urbanismo pela Universidade Federal do Ceará (1981), Mestre em Sociologia pela Universidade Federal do Ceará (1986), Doutor pelo Institute of Education of the University of London - UK (1998), Doutor em Educação pela Universidade Federal do Ceará (1999), e Pós-doutor em Filosofia da Arte e Subjetividade pela Ecole des Hautes Etudes en Sciences SocialesFR. Atualmente é Professor Associado da Universidade Federal do Ceará, lotado na FACED/UFC

** Graduada em Serviço Social pela Universidade Estadual do Ceará (2006) e mestra em Políticas Públicas e Sociedade pela Universidade Estadual do Ceará (2008). Atualmente é Assistente Social do IFCE - Campus de Maracanaú. 1 A classe que vive do trabalho compreende a totalidade dos assalariados, homens e mulheres que vivem da sua força de trabalho e que são despossuídos dos meios de produção. (ANTUNES, 2010) 2 Informações obtidas no site www. Ifce. edu. br < acesso em 06 de dezembro de 2011>.

ENVIADO EM: 05.12. 2011

APROVADO EM: 20.12. 2011 